\title{
Kadın Yaşamında Obezitenin Jinekolojik Etkileri
}

\author{
Gynecological Effects Of Obesity In Women's Life
}

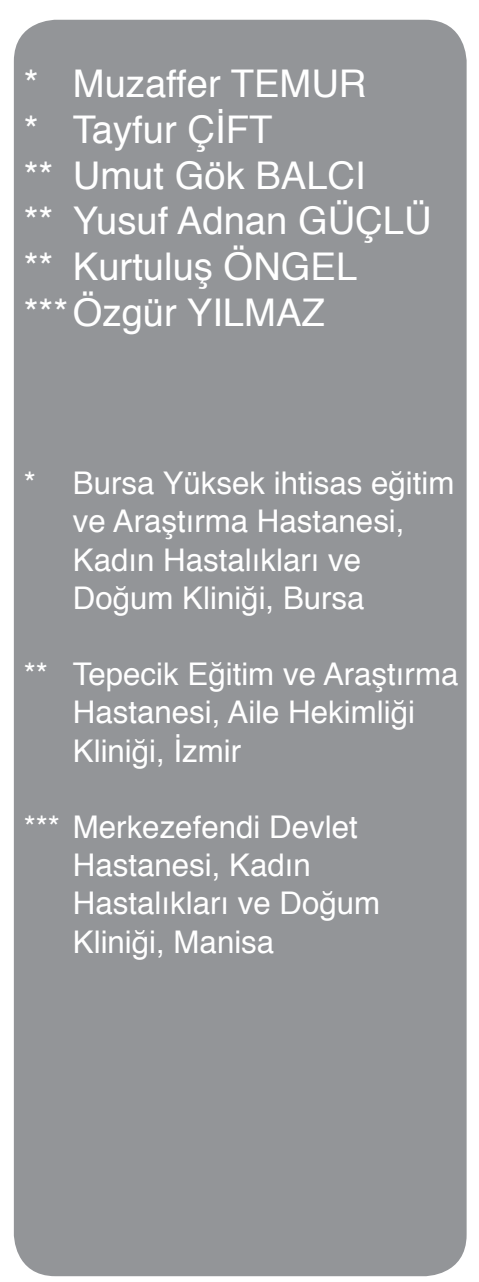

Yazışma Adresi:

Dr. Muzaffer Temur

Bursa Yüksek ihtisas eğitim ve

Araştırma Hastanesi, Kadın

Hastalıkları ve Doğum Kliniği,

Bursa

\section{Öz}

Giriş: Obezitenin prevalansı tüm yaş gruplarında artış göstermektedir. Obezite temelde hormonal çevreyi değiştirerek birçok jinekolojik soruna yol açmaktadır. Çalışmamızda obezitenin kadın yaşamına jinekolojik etkilerini ve sonuçlarını irdeledik. Gereç ve Yöntem: Çalışmamıza 195 normal kilolu (BMl:20-24.9 kg/m2) ve 104 obez kadın (BMl $\geq 30 \mathrm{~kg} / \mathrm{m} 2$ ) toplam 299 kadın dahil edildi. Çalışmaya katılan kadınların yaşları, doğum sayısı, adet düzeni, sigara içme alışkanlığı ve de eğitim düzeyi retrospektif olarak obezite ve aile hekimliği polikliniğindeki kayıtlardan incelendi ve oluşturulan formlara aktarıldı. Bulgular: Obez kadınlar ile obez olmayan kadınlar karşılaştırıldığında, obez grupta menarş yaşının daha erken görüldüğü ve kontrol grubu ile aradaki farkın istatistiksel olarak anlamlı olduğu belirlendi $(p<0,001)$. Hastaların menstrüel siklus ile ilgili bilgilerine bakıldığında obez grupta menstrel siklusun düzensiz olduğu ve gruplar arasında da istatistiksel olarak anlamlı bir farkın olduğu belirlendi $(p<0.001)$. Sonuç ve Tartışma: Sonuç olarak obezite kadınların özellikle jinekolojik yaşamında sorun oluşturmakta ve giderek büyüyen bir halk sağlığı sorunu olarak karşımıza çıkmaktadır. Bu yüzden obezite ile mücadelede kadın doğum klinisyenleri olarak, halk sağlığı uygulayıcıları ile birlikte hareket edilmelidir. Kadınların obezite ile ilgili bilgilendirme ve mücadeleye katılmalarında jinekolojik ve de obstetrik problemleri açıklayarak katkı sağlamak mümkün olacaktır.

Anahtar Kelimeler: Obezite, Menstürel düzensizlik, Menarş yaşı

\section{Abstract}

Objective: The prevalence of obesity increases both in children and adolescents and in adults. In overweight or obese young girls, gynecological problems as well as obstetric problems in their future lives also occur. In our study, we investigated gynecological effects and consequences of obesity in women's life. Materials and Methods: A total of 299 women of 195 normal weight (BMl:20-24.9 kg/m2) and 104 obese women (BMI $\geq 30 \mathrm{~kg} / \mathrm{m} 2$ ) were included in the study. The age, number of births, menstrual period, smoking habit and education level of women participating in the study were examined retrospectively from the records of the obesity and family medicine policlinic and transferred to the formed forms. Results: When obese women and nonobese women were compared, it was determined that the age of menarche 
was seen earlier in the obese group and the difference with the control group was statistically significant ( $p$ $<0.001)$. Regarding the menstrual cycle information of the patients, it was determined that the menstrual cycle was irregular in the obese group and there was a statistically significant difference between the groups ( $p<0.001)$. Conclusion: As a result, obesity is a problem especially in the gynecological life of women, and it is a growing public health problem. For this reason, as clinicians, fighting with obesity will be able to contribute to informing gynecological and obstetric problems in women by participating in informing and fighting by acting together with public health practitioners

Keywords: Obezite, Menstürel düzensizlik, Menarş yaşı

\section{Giriş}

Vücut kitle indeksinin $30 \mathrm{~kg} / \mathrm{m}^{2}$ den büyük olmas durumu obezite şeklinde değerlendirilmekte ve halk sağlığını etkileyen en önemli sorunlardan biri olarak karşımıza çıkmaktadır(1). Obezitenin prevalansı tüm yaş gruplarında artış göstermektedir. Yapılan kamu spotları, bilgilendirme panelleri, Sağlık Bakanlığı ve özel hastanelerin ortaklaşa yürüttükleri obeziteyle mücadele programlarına rağmen bu durum artış göstermeye devam etmektedir. Türkiye Halk Sağlığı Kurumu Obezite, Diyabet ve Metabolik Hastalıklar Daire Başkanlığının yaptığı "Türkiye Beslenme ve Sağlık Araştırması-2010" ön çalışma raporuna göre Türkiye'de obezite sıklığı, erkeklerde $\% 2,5$, kadınlarda ise \% 41,0 toplamda \% 30,3 olarak bulunmuştur. Toplamda fazla kilolu olanlar \%34,6, fazla kilolu ve şişman olanlar $\% 64,9$, çok şişman olanların oranı $\% 2,9$ olarak bulunmuştur(2).

Dünyada olduğu gibi ülkemizde de obezite artmakta ve obezite ile birlikte izlenen diğer problemler de çoğalmaktadır. Adolesan kızlarda obezite ile birlikte menarş yaşının etkilendiği literatürdeki çalışmalarla gösterilmiştir(3-5). Yine çalışmalarda obezitenin hayat kalitesini azaltığı yaşam süresini azalttığı gösterilmiştir. Fazla kilolu ya da obez adolesanlarda jinekolojik problemler yanında ileri yaşlarında obstetrik problemler de meydana gelmektedir.
Seksüel matürasyon ve fertilite ile ilgili bozukluklar, sosyal yaşam ile ilgili sorunlar ve sigara kullanımı, menstrüasyon değişiklikleri (sürede uzama, kanama miktarında artış), kullanılan kontrasepsiyondaetkisizlik veya yetersizlik, bunun sonucunda istenmeyen gebelik oluşumu, polikistik over sendromu, meme ve endometrial kanser riskinde artış obezitede görülen başlıca sorunlardır. Obezite ile ilgili temel obstetrik problemler gestasyonel hipertansiyon, preeklampsi, gestasyonel diyabetes mellitus, erken doğum ve primer sezaryen oranında artış sayılabilir(6-10).

Çalışmamızda obezitenin kadın yaşamına jinekolojik etkilerini ve sonuçlarını irdeledik.

\section{Gereç ve Yöntem}

Çalışmamıza 195 normal (BMI:20-24.9 kg/m²) ve 104 obez $\left(B M I \geq 30 \mathrm{~kg} / \mathrm{m}^{2}\right.$ ) toplam 299 hasta dahil edilmiştir. BMI, hastanın kilosunun boyunun karesine bölünmesi ile elde edilmiş ve kilogram/metrekare olarak hesaplanmıştır. BMI 20-24.9 arası normal hasta grubunu, BMI 30 ve üstü ise obez hasta grubunu oluşturmuştur. Hastaların yaşları, doğum sayısı, menstruel düzeni, sigara içme alışkanlığı ve de eğitim düzeyi retrospektif olarak obezite ve aile hekimliği polikliniğindeki kayıtlardan elde edilerek incelenmiş ve oluşturulan formlara aktarılmıştır.

Veriler Statistics Programme for Social Scientists for Windows 21.0 (SPSS, Chicago, IL, USA) ile değerlendirilmiș. Normal veri dağılımı KolmogorovSmirnov testi ile analiz edilmiştir. Sonuçlar ortalama \pm standart sapma olarak verilmiştir. Hastalara ait demografik karakterlere $\mathrm{t}$ test, $\mathrm{X}^{2}$ testi ve Fisher's exact testlerinden uygun olanlar uygulanmıştır.

\section{Bulgular}

104 hasta çalışma grubu(obez), 195 hasta ise kontrol grubu olmak üzre toplam 299 hasta ile çalışma gerçekleştirilmiştir. Çalışma ve kontrol grubuna ait temel demografik özelikler ve menstrüel durumları Tablo 1'de özetlenmiştir. BMI, çalıșma grubunda kontrol grubana göre yüksek belirlenmiş ve aradaki fark da istatistiksel olarak anlamlı çıkmıştır( $p<0,001)$. Obez grupta menarş yaşının daha erken görüldüğü 
ve kontrol grubu ile aradaki farkın istatistiksel olarak anlamlı olduğu belirlenmiştir $(<0,001)$

Hastaların menstrüel siklus ile ilgili bilgilerine bakıldığında (Tablo:2) obez grupta menstrel siklusun düzensiz olduğu ve gruplar arasında da istatistiksel olarak anlamlı bir farkın olduğu belirlenmiştir $(p<0.001)$

Çalıșmada hastalara ait alıșkanlıklardan sigara içiminin değerlendirildiği Tablo 3'te obez grubun \%10.4'ü çalışma grubunun ise \%18.7'sinin sigara kullandığı görülmektedir. Ancak gruplar arasında sigara içimi açısından fark istatistiksel olarak anlamlı çıkmamıştır $(p=0.843)$.

Çalışmada hastaların eğitim düzeyi Tablo 4'de özetlenmiştir. İlginç olarak obezitenin okur-yazar olmayan grupta daha düşük olduğunu belirledik $(\% 1,0)$. Obezitenin üniversite mezunu ve lise mezunlarında daha fazla oranda olduğunu belirledik(\%22,7).

$\begin{array}{lllc} & \text { Normal }(\mathbf{n}: 195) & \text { Obez }(\mathbf{n}: 104) & \text { P } \\ \text { Yaş } & 30,44 \pm 8,81 & 32,13 \pm 8,55 & 0,112 \\ \text { BMI } & 22,89 \pm 3,45 & 37,92 \pm 7,01 & <0,001 \\ \text { Gravida } & 1,10 \pm 1,44 & 1,93 \pm 1,89 & <0,001 \\ \text { Parite } & 0,87 \pm 1,08 & 1,35 \pm 1,38 & 0,004 \\ \text { Menarş yaşı } & 13,31 \pm 1,35 & 12,70 \pm 1,29 & <0,001 \\ \text { Mensturasyon Süresi } & 5,32 \pm 1,70 & 5,21 \pm 1,72 & 0,575\end{array}$

\section{Mensturel Düzen}

$\begin{array}{lc}\text { Düzenli } \mathrm{n}(\%) & \text { Normal } \\ \text { Düzensiz } \mathrm{n}(\%) & 157(52,5) \\ \text { Toplam } \mathrm{n}(\%) & 38(12,7) \\ & 195(65,2)\end{array}$

\section{Obezite Durumu}

\section{Obez}

$63(21,1)$

$41(13,7)$

$<0.001$

$104(34,8)$ 


$\begin{array}{lcc}\text { Sigara Kullanımı } & \text { Obezite Durumu } & \text { P } \\ & \text { Normal } & \text { Obez } \\ \text { İçmiyor } n(\%) & 139(46,5) & 73(24,4) \\ \text { İçiyor } \mathrm{n}(\%) & 56(18,7) & 31(10,4) \\ \text { Toplam } \mathrm{n}(\%) & 195(65,2) & 104(34,8)\end{array}$

\begin{tabular}{|c|c|c|c|}
\hline \multirow[t]{2}{*}{ Öğrenim Durumu } & \multicolumn{2}{|c|}{ Obezite Durumu } & \multirow[t]{2}{*}{$\mathbf{p}$} \\
\hline & Normal & Obez & \\
\hline - - - - - - - - - - - - - - & -------- & ---------- & -------- \\
\hline Okuryazar değil n(\%) & $2(0,7)$ & $3(1)$ & \\
\hline İlkokul n(\%) & $34(12)$ & $44(14,7)$ & \\
\hline Ortaokul n(\%) & $21(7)$ & $15(5)$ & \\
\hline Lise $n(\%)$ & $68(22,7)$ & $25(8,4)$ & $<0.001$ \\
\hline Üniversite n(\%) & $68(22,7)$ & $17(5.7)$ & \\
\hline Toplam n(\%) & $195(65,2)$ & $104(34,8)$ & \\
\hline
\end{tabular}

\section{Tartışma}

Obezite sürekli artan bir insidansa sahip olmakla birlikte toplumun tüm kesimini etkileyen bir halk sağlığı sorunu olarak karşımıza çıkmaktadır. Bu durum çocukluk, adölesan, fertil dönem, premenopozal ve postmenopozal dönemde farklı sorunlara yol açmaktadır. Çalışmamızda obezitenin kadın yaşamına jinekolojik etkilerini irdelemeyi hedefledik.

Obezitenin meydana gelişi ile ilgili hormon ya da nöropeptidler araştırıldığında bazı moleküllerin oluşumunda rol alabileceği fikri oluşmuştur.
Yapılan leptinin salgılanmasında yetersizlik ya da dirençte obezitenin meydana gelebileceğini göstermişlerdir. Yine aynı çalışmada neuropeptid Y'nin fazla salgılanması ya da leptin tarafından inhibe edilememesi de yine obezite ile sonuçlandığını belirlemişlerdir(11). Yine yapılan başka bir çalışmada farelerin hipotalamusuna neuropeptid $Y$ enjekte edilmiş. Farelerde polifaji ve obeziteye neden olduğunu belirlemişlerdir(12). Obezite gelişimi ile kaskat başlamaktadır. Leptine karşı rezistans, neuropeptid $Y$ inhibisyonunda aksamalar oluşmaktadır. Ardından insülin rezistansı ve buna bağlı olarak hastalarda menstrüel siklusta düzensizliklere ve buna bağlı 
olarak infertiliteye sebep olabilmektedir. Obez hastalarda menarş yaşı ve menstrüel siklus olumsuz yönde etkilenmektedir. Literatüre bakıldığında obezite ve menarş yaşının ayrıca menstrüel siklusda düzensizlikler olduğunu gösteren birçok çalışma vardır(4,13). 2015 yılında yapılan bir çalışmaya 220 kişi dahil edilmiş, 67 hasta obez, 49 hasta aşırı kilolu, 104 hasta normal kilolu gruplarını oluşturmuştur. Obez hastaların \%24'ünde, aşırı kilolu hastaların ise \%14,09'unda menstrüel düzensizlikler izlenirken normal kilolu hasta grubunda menstrüel düzensizliği sadece \%9,5 olarak belirlemişlerdir. Çalışmada Obez grupta belirgin şekilde menstrüel düzensizlik olduğu göze çarpmaktadır(14). Yine marzouk ve arkadaşlarının yaptığı çalışmada obezitenin adolesanlarda polikistik over hastalığına ve bunula beraber seyreden menstrüel düzensizliklere katkıda bulunduğu, kilo kaybının ise bu semptomları azalttığı gözlenmiştir.(15) Bu çalışmaların aksine panidis ve arkadaşları ise menstrüel düzensizliğin obez ve normal kilolu hastalar arasında değişmediğini savunmuşlardır.(16) Bizim yaptığımız çalışmada ise obez grupla kontrol grubunun karşılaştırılması sonucu obez grupta menstrüel düzensizliğin daha sık izlendiği belirledik. Bunun sebebi hala araştırma konusu olmakla beraber adipoz dokunun endokrin organ gibi hormon üretimi ve metabolizmasında görev alması ve bu hormanların ovaryan siklusu etkileyerek menstürel düzensizliklere sebep olması birçok çalışma da gösterilmiştir. $(17,18)$

Sigara içimi ve obezitenin birlikte olduğu hasta gruplarında zararlı etkilerin çok daha fazla olduğu yönünde bildirimler yapılmıştır. García ve arkadaşlarının yaptığı çalışmada obez hastalarda sigara içimine ara verilmesinin mortalite ve morbiditede azalmayı sağladığını belirlemişlerdir(19). Başka bir çalışmada sigara içiminin özelikle genç ve hali hazırda ağır bir şekilde sigara içmeye devam eden insanlarda obeziteye karşı koruyucu olduğu fikrinin basit ötesi bir inanış olduğu, sigara içimine ara vermenin de geçici olarak kilo almaya neden olduğu tespit edilmiştir.(20). Bizim çalışmamızda ise obez hasta grubunda sigara içimi oranlarının kontrol grubuna göre daha düşük oranda olduğunu belirledik. $\mathrm{Bu}$ durumun obezite ile birlikte sigara içiminin riski artırması nedeniyle sigara içiminden uzak durulduğu mu ya da sosyal bir nedene mi bağlı olduğu geniş çaplı prospektif çalışmalarla araştırılmasının mümkün olacağını öngörmekteyiz.

Sonuç olarak obezite kadınların özellikle jinekolojik yaşamında hormonal düzensizliğe sebep olarak ve bununla bağlantılı olarak adet düzensizliklerine sebep olmakta ve giderek büyüyen bir halk sağlığı sorunu olarak karşımıza çıkmaktadır. Bu yüzden obezite ile mücadelede klinisyenler olarak, halk sağlığı uygulayıcıları ile birlikte hareket ederek bilgilendirme ve mücadeleye katılmalarında kadınlara jinekolojik ve de obstetrik problemleri açıklayarak katkı sağlamak mümkün olacaktır.

\section{Kaynaklar}

1. Yang, L., \& Colditz, G.A.. Prevalence of overweight and obesity in the United States, 2007-2012. JAMA internal medicine, (2015)175(8), 1412-1413.

2. www.sagem.gov.tr/TBSA_Beslenme_Tayini:Pdf

3. Wang $\mathrm{H}$, Xue $\mathrm{H}$, Du S, Zhang J, Wang Y, Zhang $B$. Time trends and factors in body mass index and obesity among children in China: 1997 to 2011. Int J Obes (Lond). 2017 Feb 27. doi: 10.1038/ijo.2017.53.

4. Chitnis T, Graves J, Weinstock-Guttman B, Belman A, Olsen C, et al. U.S. Network of Pediatric MS Centers. Distinct effects of obesity and puberty on risk and age at onset of pediatric MS. Ann Clin Transl Neurol. 2016 Nov 4;3(12):897-907

5. Ersu A, Ersu NK, Balcı UG, Öngel K. Dört Morbid Obez Hastanın Takipleri: Olgu Serisi. Smyrna Tıp Dergisi 2015;5(3):50-51.

6.Elizondo-Montemayor L, Hernández-Escobar C, Lara-Torre E, Nieblas B, Gómez-Carmona M. Gynecologic and Obstetric Consequences of Obesity in Adolescent Girls. J Pediatr Adolesc Gynecol. 2016 Feb 22. pii: S1083-3188(16)00182-0.

7. Broughton DE, Moley $\mathrm{KH}$. Obesity and female infertility: potential mediators of obesity's impact. Fertil Steril. 2017 Mar 11. pii: S0015-0282(17)30060-2. 8. McDonald SD, Han Z, Mulla S, Beyene J; Knowledge Synthesis Group. Overweight and obesity in mothers and risk of preterm birth and low birth weight infants: systematic review and meta-analyses. BMJ 341: c3428, 2010

9. Hildén K, Hanson U, Persson M, Fadl H. Overweight 
and obesity: a remaining problem in women treated for severe gestational diabetes. Diabet Med 33: 1045-1051, 2016

10. Spradley FT. Metabolic abnormalities and obesity's impact on the risk for developing preeclampsia. Am J Physiol Regul Integr Comp Physiol. 2017 Jan 1;312(1):R5-R12.

11. Deniz G, Saygı Ş.Leptin, neuropeptide $Y$ and Obesity. Turkish Clinic. J Med Sci 2002;22(2):217-20 12. Stainly BG, Kyrkouli SE, Lampert S, Leibowitz SF, Neuropeptide $Y$ chronically injected into the hypothalamus is powerful neurochemical inducer of hyperphagia and obesity. Peptides 1986 NovDec;7(6):1189-92.

13. Hartz AJ, Barboriak PN, Wong A, Katayama KP, Rimm AA, 1979 The association of obesity with infertility and related menstural abnormalities in women. Int J Obes 3: 57-73.

14. Mustaqeem M, Sadullah S, Waqar W, Farooq MZ, Khan A, Fraz TR. Obesity with irregular menstrual cycle in young girls. Mymensingh Med J. 2015 Jan;24(1):161-7.

15. Marzouk TM, Sayed Ahmed WA. Effect of Dietary Weight Loss on Menstrual Regularity in Obese Young Adult Women with Polycystic Ovary Syndrome J Pediatr Adolesc Gynecol. 2015 Dec;28(6):457-61.

16. Panidis D, Tziomalos K, Papadakis E, Chatzis $P$, Kandaraki EA, Tsourdi EA, Macut D, Bjekic-Macut J, Marthopoulos A, Katsikis I.Associations of menstrual cycle irregularities with age, obesity and phenotype in patients with polycystic ovary syndrome. Hormones (Athens). 2015 Jul-Sep;14(3):431-7.

17. Wei S, Schmidt MD, Dwyer T, Norman RJ, Venn AJ. Obesity and menstrual irregularity: associations with SHBG, testosterone, and insulin.Obesity (Silver Spring). 2009 May;17(5):1070-6. doi: 10.1038/ oby.2008.641.

18. Weiss DJ, Charles MA, Dunaif A, Prior DE, Lillioja S, Knowler WC, Herman WH.

Hyperinsulinemia is associated with menstrual irregularity and altered serum androgens in Pima Indian women. Metabolism. 1994 Jul;43(7):803-7.

19. García Álvarez A, Serra-Majem L, Castell C, Ribas-Barba L, Méndez MA. Trends in the association between smoking history and general/central obesity in Catalonia, Spain (1992-2003). Nutr Hosp. 2017 Feb $1 ; 34(1): 102-110$.
20. Dare S, Mackay DF, Pell JP. Relationship between smoking and obesity: a cross-sectional study of 499,504 middle-aged adults in the UK general population. PLoS One. 2015 Apr 17;10(4):e0123579. 